\title{
Newly developed histological tray for the application of identifying exact lymph node dissections in urological surgical oncology
}

\author{
Istvan Buzogany ${ }^{1}$, Laszlo Vaczi ${ }^{1}$, Zsolt Domjan ${ }^{1}$, Fariborz Bagheri ${ }^{2}$, Attila Kiss ${ }^{1}$, \\ Alex Dakay ${ }^{1}$, Tamas Ferenc Molnar ${ }^{3,4}$ \\ ${ }^{1}$ Department of Urology and Surgery, Péterfy Sándor Hospital KRBK, Budapest, Hungary; istvan.buzogany@gmail.com \\ ${ }^{2}$ Department of Urology, Dubai Hospital, Dubai, UAE \\ ${ }^{3}$ Petz Aladár Hospital MK, Department of Thoracic Surgery, Györ, Hungary \\ ${ }^{4}$ Operational Medicine Department, University Medical School Pécs, Pécs, Hugary
}

Received 26 July 2013; revised 26 August 2013; accepted 15 September 2013

Copyright (C) 2013 Istvan Buzogany et al. This is an open access article distributed under the Creative Commons Attribution License, which permits unrestricted use, distribution, and reproduction in any medium, provided the original work is properly cited.

\begin{abstract}
In any urologic cancer surgery, lymph node dissection and its processing play a significant role in staging and management of the patients. Accordingly, precise handling of the dissected lymph nodes is important for histopathological work-up. The authors have developed a lymph node plastic tray shaping the abdomen and pelvis in which the dissected lymph nodes are placed in its determined location. This can be applied for any urologic cancer surgery. The research was designed to test the usage of a new histological tray. The objective was to assess how helpful it was for the surgical team and in the pathological process. The newly developed lymph node tray has been applied in $\mathbf{1 5 0}$ urological cancer surgeries and its efficacy and outcome have been evaluated in all these cases by involved doctors and assistants. This new tray simplifies lymph node removing and identification (staging), making it safer and quicker in any uro-oncological surgery. It facilitates the work of the pathologist and the flow of reliable information along the surgeon-pathologist-oncologist team. With usage of the tray, lymph node dissections are more structured by methodical means compared to any of the present methods.
\end{abstract}

Keywords: Lymph Node Dissection; Urogenital Surgical Oncology; TNM System; Safety and Hazards; Histological Tray

\section{INTRODUCTION}

Surgical removal of the lymph nodes for biopsy and staging is an essential procedure in most oncological surgeries. In urological cancer surgeries, lymph node dissection and precise localization of the excised lymph node are crucial for staging and further management of the patient. Since 1970s, systemic lymph node removal and histological processing has become an important component of surgical strategy [1]. Frequently questioned are the issues of lymph node dissection in testicular, bladder, and prostate cancer surgeries [2-4]. The lymph nodes that shall be removed and intended for pathological examination must be dissected from the optimal anatomical region and meet the professional recommendations and urological surgical guidelines [3,5]. The therapeutic and /or prognostic value of local and distant lymph node removal is not always straightforward.

TNM staging (T-tumor, N-lymph nodes, M-metastases) of some tumors contains similar elements, but there are significant differences between the practice and performance disciplines of manual lymph node dissections [4,68]. During lymph node dissections, mistakes can be made, and the possibility to avoid these situations shows similarities. These similarities have required standard methods of surgery and a single transport system which is standard, simple, has transparency, and easy for everyone $[9,10]$.

Our goal was to adapt and test the sampling methods in uro-oncological surgery, which is used by head-neck and throacic surgery.

\section{MATERIALS AND METHODS}

The retroperitoneal space and pelvis region are common areas for several specialties including, urological, gynecological and general surgical cancer surgeries. The fully developed and tested retroperitoneal and pelvic lymph node tray serve the common needs of all three 
specialties (Figure 1). The size of the tray is the same as the previously designed and routinely used $30 \times 20 \mathrm{~cm}$ tray used in otolaryngology. The volume of each compartment is $20 \mathrm{ml}$, with a depth of $40 \mathrm{~mm}$, a diameter of $30 \mathrm{~mm}$, and each compartment has a rubber airtight seal. The orientation serves the main anatomical structures, such as the inferior vena cava, abdominal aorta, renal arteries and veins, and the iliac vessels. In addition, the retroperitoneal templates were designed with a special compartment on each side, with three presacral iliac lymph node samples to accommodate a crucible. All containers are designated by a reference to facilitate the initial documentation of the topographic anatomical location. We label the removed lymph nodes from the abdominal cavity on the crucible with A-1, 2, 3 etc., and from the pelvis with $\mathrm{P}-1,2,3$ etc. (Figure 2). The transportation of the samples to the pathology lab is imperatively uniform. The order of letters and numbers shown on the plates will be recorded for each removed lymph node.

In the case of testicular and kidney tumors, the patterns are similar in the testis and kidney tumors in areas primarily in the kidney area of the common iliac (A /abdominal/tray). For prostate and bladder tumors, the samples are removed and taken from the aortic bifurcation $(\mathrm{P} /$ pelvic/tray).

The plastic lymph node tray is in accordance with the location of the individual crucibles in the outlined retroperitoneal anatomical region, pelvic lymph node anatomical position and, accordingly, are dissected during surgery directly and placed in the tray on the operating table. The tray with molded plastic containers containing samples in formalin, is fixed and transported after sealing with a tight rubber cap (Figure 3). The removal of lymph nodes and application of the tray can be safely used in accordance with the standardized guideline requirements. The surgeon, assistant, and scrub nurse can prepare the entire sterile dissections and fully transport

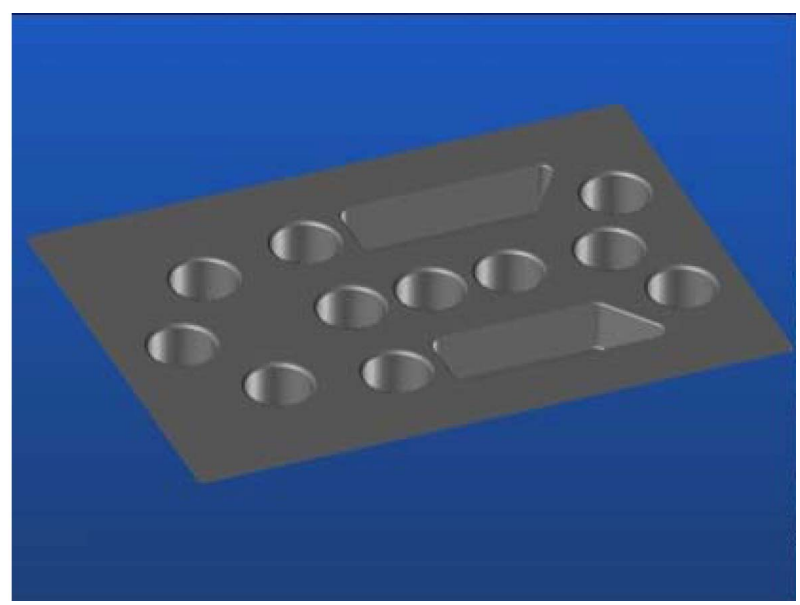

Figure 1. The tray used in urology. them without any interference. Sterilization of the tray can be done by formaldehyde vapor or plasma sterilization.

\section{RESULTS}

Between 2009 and 2012, a total of 150 samples were transported by our newly developed lymph node tray. Specimens were placed into crucibles ten out of 50 - 50 times during retropubical radical prostatectomies, and cystectomies, then times during salvage lymphadenec-

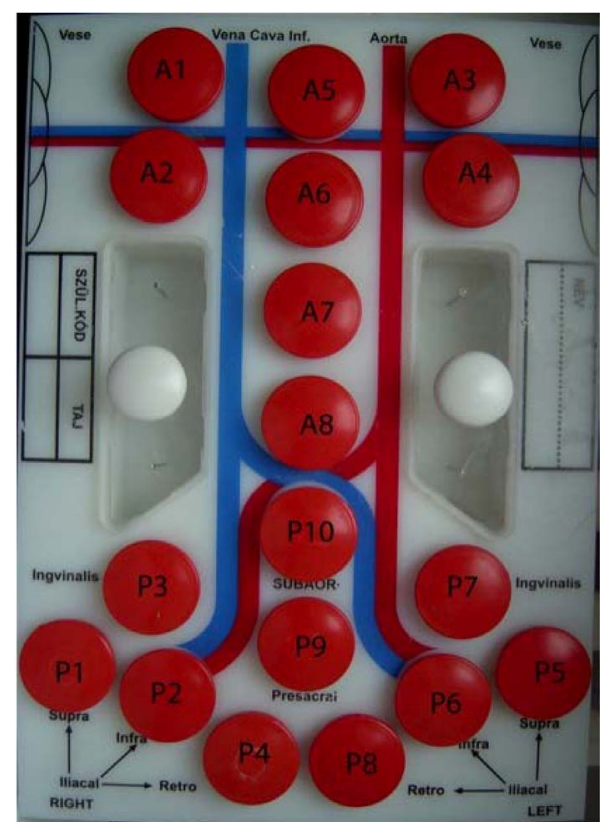

Figure 2. Abdominal (A) and Pelvic (P) combined tray.

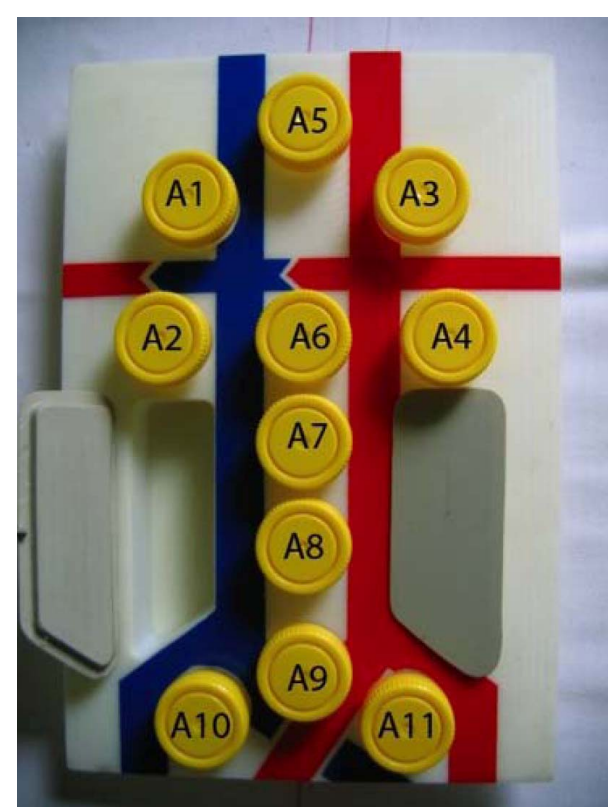

Figure 3. Abdominal tray. 
tomies, and forty times during radical nephrectomies. Ten patients with prostate cancer were tested using our method and the results of histological samples were compared to be examined for pre-and post-operative TNM staging. Five samples were found having a higher pathological stage in the preoperative period. In four cases, one was positive. With Three times in the $\mathrm{T}$ stage is found to be higher, with 2 cases of $\mathrm{T}$ and $\mathrm{N}$ increases, only one sample $\mathrm{T}$ positivity seen for the same lymph node status. Only one time was the lymph node positivity observed under the same T stage (Table 1).

During a 12 month period, evaluation of the device and the method of application were conducted among personnel (2 urological surgeons-operator, 4 urological surgical assistants, 3 scrub nurses, 3 scrub nurse assistants, and 2 pathologists). The evaluation of the histological samples by operating room personnel was performed significantly better after exceptional storage and transport. Based on the evaluation result of the surgeons, the new lymph node tray was more transparent reducing the possibility of mistakes. Pathologists showed clear emphasis and positive comments on the simplicity and reliability of the processing. Only the pathological assistants found the usage of the trays not to be easy (Table 2). Overall, the use of the device has made it easier to keep track of processes, health, and safety regulations. The process of minimizing the number of interactions between staff clarified the course of the process. It is quick, simple, and can be done to improve safety.

In accordance with the removal of lymph nodes in the order of completed forms, the application of the tray has clearly improved conditions for the processing of tissue samples based on the opinions of surgical operating room and pathological staff. The authors' use of devices has gained similar positive experience, compared with the former head-neck and thoracic surgery.

Table 1. Lymph node samples of the patients going under radical prostatectomy in 10 cases.

\begin{tabular}{|c|c|c|c|c|}
\hline & TRUS stage & Removed region & Positive lymph node & Final stage \\
\hline 1 & $\mathrm{~T} 2 \mathrm{cN} 0 \mathrm{M} 0$ & IILN & Neg. & $\begin{array}{c}\text { pT2cN0M0 } \\
(\leftrightarrow)(-)\end{array}$ \\
\hline 2 & $\mathrm{~T} 2 \mathrm{cN} 0 \mathrm{M} 0$ & SILN, IILN PILN, PSLN & RsIILN 12/2 & pT3bN1M0 (†) $(+)$ \\
\hline 3 & T3aN0M0 & SILN, IILN PILN, PSLN & Neg. & $\begin{array}{c}\mathrm{pT} 2 \mathrm{cN} 0 \mathrm{M} 0 \\
(\downarrow)(-)\end{array}$ \\
\hline 4 & $\mathrm{~T} 2 \mathrm{cN} 0 \mathrm{M} 0$ & SILN, IILN PILN, PSLN & Neg. & $\begin{array}{c}\text { T2cN0M0 } \\
(\leftrightarrow)(-)\end{array}$ \\
\hline 5 & T2cN0M0 & IILN & $\begin{array}{l}\text { RsIILN 17/1 } \\
\text { LsIILN 18/2 }\end{array}$ & $\begin{array}{c}\text { pT2cN1M0 } \\
(\leftrightarrow)(+)\end{array}$ \\
\hline 6 & T2aN0M0 & IILN & $\mathrm{Neg}$ & $\begin{array}{c}\text { pT2aN0M0 } \\
(\leftrightarrow)(-)\end{array}$ \\
\hline 7 & T2cNoMo & SILN, IILN PILN, PSLN & RsSILN 12/2 & $\begin{array}{c}\text { pT3aN1M0 } \\
(\uparrow)(+)\end{array}$ \\
\hline 8 & T2aN0M0 & IILN & Neg & $\begin{array}{c}\text { pT2c N0M0 } \\
(\uparrow)(-)\end{array}$ \\
\hline 9 & T3aN0M0 & SILN, IILN PILN, PSLN & $\begin{array}{l}\text { RsPSLN 8/2 } \\
\text { LsSILN } \\
\text { LsIILN 16/3 } \\
\text { LsPSLN 1/1 }\end{array}$ & $\begin{array}{c}\text { T3aN2M0 } \\
(\leftrightarrow)(+)\end{array}$ \\
\hline 10 & T2cN0M0 & SILN, IILN PILN, PSLN & $\mathrm{Neg}$ & $\begin{array}{c}\text { pT2cN0M0 } \\
(\leftrightarrow)(-)\end{array}$ \\
\hline
\end{tabular}

SILN: superior iliac lymph node; IILN: inferior iliac lymph node; PILN: para iliac lymph node; PSLN: pre-sacral lymph node; Rs: right side; Ls: left side; ( $\leftrightarrow$ ) unchanged T-stage; $(\uparrow)$ increased T-stage; $(\downarrow)$ decreased T-stage; $(+)$ lymph node proved to be positive compared to staging; $(-)$ state of the lymph node was the same as during staging.

Table 2. The evaluation of the questionnaire using the urologic histological tray.

\begin{tabular}{|c|c|c|c|c|c|c|c|c|}
\hline & \multicolumn{2}{|c|}{ easier } & \multicolumn{2}{|c|}{ safer } & \multicolumn{2}{|c|}{ Easier to document } & \multicolumn{2}{|c|}{ faster } \\
\hline & yes & no & yes & no & Yes & no & yes & no \\
\hline Operating surgeon & $\mathrm{X}$ & & $\mathrm{X}$ & & $\mathrm{X}$ & & $\mathrm{X}$ & \\
\hline Operating assistant & $\mathrm{X}$ & & $\mathrm{X}$ & & $\mathrm{X}$ & & $\mathrm{X}$ & \\
\hline Scrub nurse & $\mathrm{X}$ & & $X$ & & $X$ & & $\mathrm{X}$ & \\
\hline Pathologist & & & $\mathrm{X}$ & & $\mathrm{X}$ & & & $\mathrm{X}$ \\
\hline Assistant pathologist & & $\mathrm{X}$ & & & & & $\mathrm{X}$ & \\
\hline Total & 4 & 1 & 5 & 0 & 5 & 0 & 4 & 1 \\
\hline
\end{tabular}


Table 3. Threatening elements of the operating activity $[9,11]$.

1. Distraction:

1. a: Talking: Distraction from the process of the operation, unnecessary noise

1. b: Motion in the operating theater: problems with sterility, distraction

Points of distraction: surgeon/scrub nurse/orderlies/transportation.

Luxurious threats: music, cell phone, arrival of inadequate external information $>$ forced decision, training of anesthetists, door slamming, "visitors"

2. Loss of information and human errors:

2. a: Patient name/data

2. b: Source/orientation of the specimen, accuracy of the localization (sequence)

3. Post operating room

3. a Transportation-exchange, physical damage

3. b: During the "transfer to glasses" in the pathology department/institute further distortion, damage of the information indicating the precise source of the sample

\section{DISCUSSION}

The potential errors that can be found during an oncological operation are obvious, general and international, but cannot be eliminated in each case (Table 3) $[5,6$, 9-12].

Methodology of lymph node processing is different in each institute.

Generally, there are common elements in every intervention. Speaking independently of the anatomical region and exploration, the operating doctor hands over the lymph nodes to the scrub nurse and gives verbal instructtion regarding its origin and sample. The scrub nurse gives over the specimen to her assistant (circulating nurse) similarly in verbal instruction. During this time, the scrub nurse is not able to pay attention to the operation, and the surgeon. The circulating nurse involved in the following steps is not able to concentrate temporarily on the operation. This process can be repeated $4-20$ times in every surgery depending on the type of operation and the number of lymph nodes removed. In fortunate cases, these chains of actions may be straightforward. In some cases, some of these actions create additional noise, leading to possible reasons for misunderstanding. The awareness of the problems can be immediately resolved and corrected instantly. Depending on the local practice, the samples will be placed into $10-20 \mathrm{ml}$ glasses labeled one by one. They are kept together and allocated by orderlies to the pathological department. The detailed chain of work would not be interesting from the surgeon's point of view, if the possible points of failure would not lead to serious medical and legal consequences $[9,10]$.

\section{CONCLUSIONS}

The natural to the operating room communication is not uniformly standardized. This is true for processing of the lymph node samples as well. Introduction of a new lymph node tray improves precise location and handling of the tissues.

For the solution of the outlined issues, with improvement of a former notion [9], we have created a lymph node tray. This tray illustrates the anatomical position of important lymph nodes and develops a method for working in a unified way. In this method, the removed tissues can be placed in the tray by the surgeon himself. The goal of our method is to localize the removed lymph nodes appropriately in the tray in order to recognize the exact anatomical position of the lymph node.

\section{REFERENCES}

[1] Donohue, J.P., Thornhill, J.A., Foster, R.S., et al. (1993) Retroperitoneal lymphadenectomy for clinical stage A testis cancer (1965 to 1989): Modifications of technique and impact on ejaculation. Journal of Urology, 149, 237243.

[2] Heidenreich, A., Varga, Z. and Von Knobloch, R. (2002) Extended pelvic lymphadenectomy in patients undergoing radical prostatectomy: High incidence of lymph node metastasis. Journal of Urology, 167, 1681-1686. http://dx.doi.org/10.1016/S0022-5347(05)65177-4

[3] Kim, D.S., Lee, Y.H., Cho, K.S., et al. (2010) Lymphovascular invasion and $\mathrm{pT}$ stage are prognostic factors in patients treated with radical nephroureterectomy for localized upper urinary tract transitional cell carcinoma. Urology, 75, 328-332. http://dx.doi.org/10.1016/j.urology.2009.07.1350

[4] Blom, J.H., van Poppel, H., Maréchal, J.M., et al. (2009) EORTC Genitourinary Tract Cancer Group. Radical nephrectomy with and without lymph-node dissection: Final results of European Organization for Research and Treatment of Cancer (EORTC) randomized phase 3 trial 30881. European Urology, 55, 28-34. http://dx.doi.org/10.1016/j.eururo.2008.09.052

[5] Jensen, J.B., Ulhøi, B.P. and Jensen, K.M. (2010) Lymph node mapping in patients with bladder cancer undergoing radical cystectomy and lymph node dissection to the level 
of the inferior mesenteric artery. BJU International, 106, 199-205.

http://dx.doi.org/10.1111/j.1464-410X.2009.09118.x

[6] Vazina, A., Dugi, D., Shariat, S.F., et al. (2004) Stage specific lymph node metastasis mapping in radical cystictomy specimens. Journal of Urology, 171, 1830-1634. http://dx.doi.org/10.1097/01.ju.0000121604.58067.95

[7] Bhayani, S.B., Ong, A., Oh, W.K., Kantoff, P.W. and Kavoussi, L.R. (2003) Laparoscopic retroperitoneal lymph node dissection for clinical stage I nonseminomatous germ cell testicular cancer: A long-term update. Urology, 62, 324-327. http://dx.doi.org/10.1016/S0090-4295(03)00324-8

[8] Burkhard, F.C., Schumacher, M. and Studer, U.E. (2005) The role of lymphadenectomy in prostate cancer. Nature Clinical Practice Urology, 2, 336-342. http://dx.doi.org/10.1038/ncpuro0245

[9] Molnar, T.F. (2007) A new device for the identification of lymph nodes at lung cancer surgery. European Journal of Cardio-Thoracic surgery, 31, 311-312. http://dx.doi.org/10.1016/j.ejcts.2006.11.047

[10] Gerlinger, I., Molnar, T.F., Jarai, T., Móricz, P., Rath, G. and Göbel G. (2010) A new device for the identification of lymph nodes removed during different types of neck dissection. Health, 2, 1093-1096. http://dx.doi.org/10.4236/health.2010.29161

[11] Papaspyros, S.C., Javangula, K.C., Adluri, R.K.P. and O'Regan, D.J. (2010) Briefing and debriefing in the cardiac operating room. Analysis of impact on theatre team attitude and patient safety. Interactive Cardiovascular and Thoracic Surgery, 10, 43-47. http://dx.doi.org/10.1510/icvts.2009.217356

[12] Janetschek, G., Hobisch, A., Peschel, R., et al. (2000) Laparoscopic retyroperitoneal lymph node dissection for clinical stage I non-seminomatous testicular carcinoma: Long-term outcome. Journal of Urology, 163, 1793-1796. http://dx.doi.org/10.1016/S0022-5347(05)67545-3 http://dx.doi.org/10.1097/00005392-200006000-00037 